\title{
The Strategies Management in the TNHEIs and the Outcome
}

\author{
Ping Song ${ }^{1}$, Fei $\mathrm{Ma}^{2}$ and Fan Qiu ${ }^{3}$ \\ ${ }^{1}$ Jiangsu Vocational College of Medicine, Jiangsu, China \\ ${ }^{2}$ Yancheng Teachers University, Jiangsu, China \\ ${ }^{3}$ Jiangsu Vocational College of Medicine, Jiangsu, China
}

Keywords: TNHEIs; manage; institution and program

\begin{abstract}
The purpose of this research is aimed to reveal the strategy and operations management in the Transnational Higher Education Institutions in China. The participating TNHEIs are sampled in Jiangsu Province. It has been found out that in the sampled TNHEIs, the management and teaching staff have perceived different level of strategy planning in a number of aspects significantly. In operations management, only few factors has been perceived differently. However, in the suggestion of improvement of the strategy and operations management, the two groups have performed considerably differently, again. It is a strange phenomenon that the operations management could be executed smoothly with huge gap in strategy management.
\end{abstract}

\section{Introduction}

In the past three decades, China becomes an increasingly popular market for International Higher Education and Transnational Higher Education (TNHE). Comparing to International Education, TNHE usually refers to a project which offers the education provision from one country in another. It has become increasingly popular globally, including mainland China, for a number of reasons that in both the market and suppliers believe the mutual benefit could be achieved. For now, the phenomenon shows no signs of any kind of slowing down, from the national data to individual Transnational Education Institutions (TNHEIs).

\section{Organization of the Text}

\subsection{Methods}

For this study, 7 TNHEIs which locates back in China had been contacted for the purpose of investigating the strategic and operations management of the TNHE programs. 3 of them participated in the research, provided 74 valid responses in accordance of the requirement which was provided initially to the TNHEIs.

The 3 TNHEIs are major higher education providers in Jiangsu Province of China. The province is reputable in HE sector nationally. According to Ministry of Education of the PRC (2015), 126 state universities and colleges operated under the supervision of the MoE whereas hundreds of TNE institutions, which are categorised as private education sector, provide internationalised education.

\subsection{Results}

Generally, Higher Education, or at least state owned Higher Education sector, is defined explicitly non-profitable. Explained by the MoE, the international or transnational education programs were intended to be a method of enriching the academic and research strength of an HEI which would like to seek resources overseas. Nevertheless, each province might have decided the development plan of the HEIs in the region for an international development.

Comparing the perceived achievement, international mobility is the most satisfactory, as well as the improvement of the teaching staff and providing opportunities for students to study overseas, 
while international mobility is not improved as much as they expected. Although the financial and other institutional perspective was not emphasised more than the other factors, the achievement in regard of generating revenue, building brand, and reacting government influence are much lower rated than the other factors.

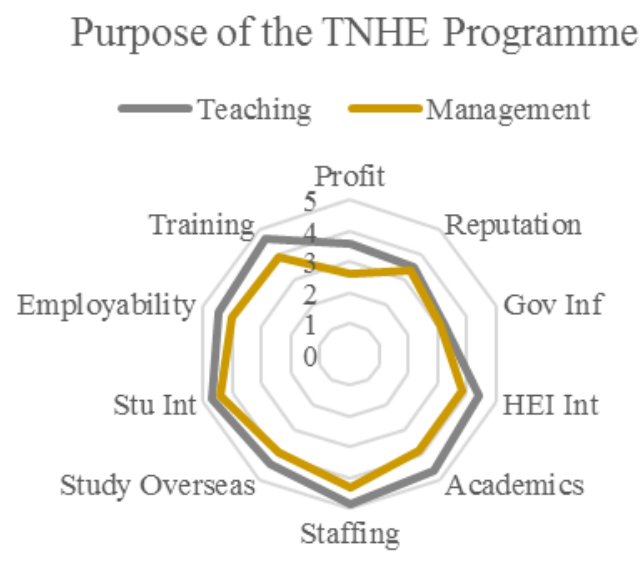

Figure 1. Purpose of the TNHE Programme

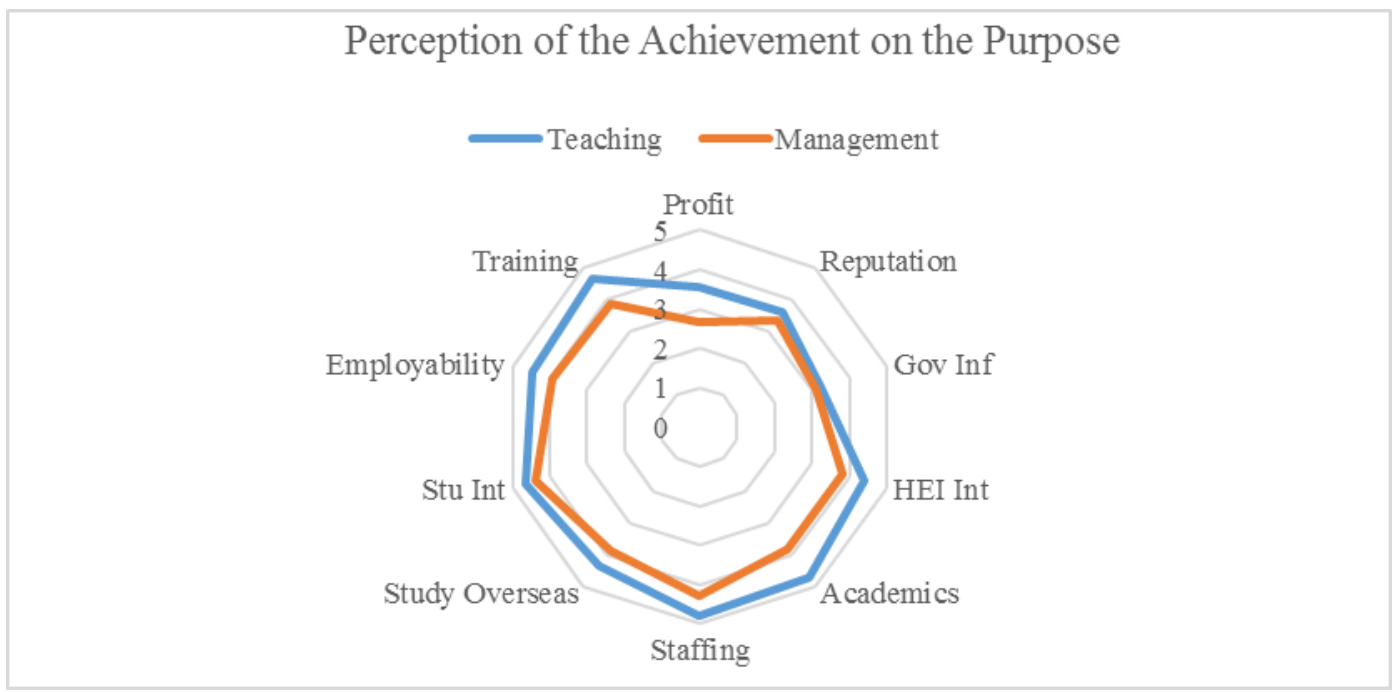

Figure 2. Perception of the Achievement of the Purpose

For the change to be made upon the strategy, the 3 TNHEIs considered that international mobility, employability, and opportunities of overseas study are most ungently to be revisited. Although not satisfied for financial and other institutional aspects, they do not think the change on them is a must-do as much as the other perspectives.

Improvement Suggested Based on the Perception

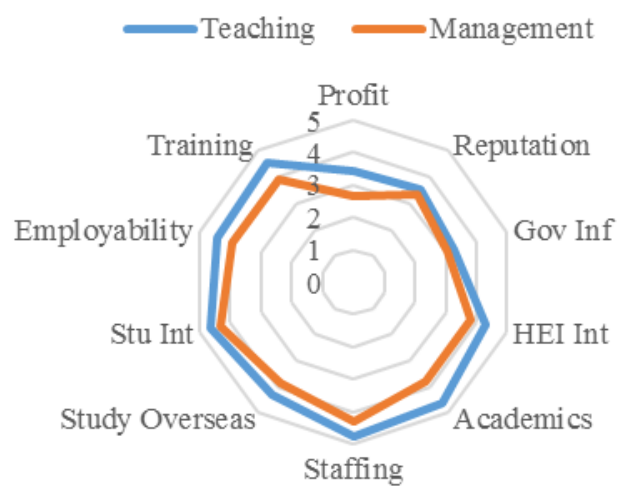

Figure 3. Improvement Suggested Based on the Perception 
In the planning stage of the programmes, the teaching and managerial staff did not have the same perception of the strategy in 7 factors. Although they both agreed that the programmes was planned in strategy of increasing the international mobility of the perspective and current students, as well as a bright strategy for building the brand of the HEIs, the teaching staff considered that the programmes benefits the institutional financial status for generation increased revenue, improving the academic strength, enhancing the students' employability, and providing unique measure for the teaching staff to improve themselves in academics and researches. The managerial staff disbelieve that the programmes benefited the financial status of the institutions, which was rated the lowest among all 10 factors. And interestingly, they also disbelieve that the programmes were designed to be a strategy to improve the academics and research capability of the institution significantly, comparing with the perceptions of the teaching staff.

\section{Conclusion}

The strategy in the TNHEIs in Jiangsu focuses on Curriculum and Pedagogy, which reflected in the emphasis on increasing the academics and research capability, improving the human resources of the TNHEIs, enhancing the employability of student, increasing the international mobility of student, and improving the academics and cultural exchanges internationally. The focus of the strategy in the TNHEIs are more internal customers oriented and covering learning Innovation and Learning Perspective. The result reinforced Gu and Schweisfurth's (2015) result that open-mind to the internationalised education is the trait in operations.

At the moment, it is impossible to review the actual strategic plan of the TNHEIs which was not explicitly recorded explicitly on the published materials such as website, brochures, staff or student handbooks, or the internal files. It is also partially revealed that the Chinese management is a policy driven style over other patterns. While an organisation is managed by policy which intends to be short term rather than long term, the strategy and other institutional level perception in the organisation intends to be unstable, so does outcome of the strategy. Therefore, it has also been found that the TNHEIs' strategy was not clearly recognised that the teaching and managerial staff perceived and reported the strategy differently.

\section{References}

[1] Al-Zwyalif, I. M. (2012). The possibility of implementing balanced scorecard in Jordanian private universities. International Business Research, 5(11), p113.

[2] Altbach, P. G. (2007). Peripheries and Centres: Research Universities in Developing Countries. Higher Education Management and Policy, 19(2), 1-24.

[3] Becker, R. (2015). International branch campuses: New trends and directions. International Higher Education, (58).

[4] Bhanji, Z. (2008). Transnational corporations in education: filling the governance gap through new social norms and market multilateralism? Globalisation, Societies and Education, 6(1), 55-73.

[5] Bryman, A. (2012). Social research methods. Oxford university press.

[6] Debowski, S. (2008). Risky business: Effective planning and management of transnational teaching. In L. Dunn \& M. Wallace (Eds.), Teaching in transnational higher education: enhancing learning for offshore international students (1st ed., pp. 204-215). New York: Routledge.

[7] Evans, S., \& Morrison, B. (2011). Meeting the challenges of English-medium higher education: The first-year experience in Hong Kong. English for Specific Purposes, 30(3), 198-208.

[8] Frater, T. (2015). Jamaica's Policy Toward GATS. International Higher Education, (53).

[9] Green, M. F., Marmolejo, F., \&Egron-Polak, E. (2012). The internationalization of higher education. The SAGE handbook of international higher education, 439. 
[10] Griggs, V., Blackburn, M., \& Smith, J. (2012). The educational scorecard: The Start of our Journey. Electronic Journal of Business Research Methods, 10(2), 121-131 